\title{
A PROBLEMÁTICA DE ESCRITA NO ENSINO SUPERIOR EM ANGOLA:
} INSTRUMENTOS DE REMEDIAÇÃO

\author{
Luzonzo Filipe*
}

RESUMO: este artigo faz uma abordagem sobre a problemática de escrita, com maior incidência aos erros ortográficos e à produção textual dos estudantes da Faculdade de Ciências Sociais de Luanda - Angola. O trabalho tem por objetivo geral elevar o nível de competência escrita dos discentes. Especificamente, pretendemos identificar e classificar os erros registados nos textos e analisar alguns aspetos relacionados com a produção textual, particularmente, a coerência e coesão. Em seguida, pesquisarmos sobre as causas dos problemas apresentados e, finalmente, propormos os instrumentos didáticos que possam ser utilizados na busca de soluções adequadas. A existência em Angola da coabitação de várias línguas, nomeadamente, a Língua Portuguesa e as línguas nacionais (kikongo, Kimbundu, umbundu, etc.), levou-nos a determinar primeiro a situação sociolinguística de cada um dos aprendentes antes de implementarmos o projeto. Os dados foram recolhidos através de um inquérito (individual) e de produção de texto. Feita a análise, constatámos que os erros mais frequentes foram os de omissão de acentos, os de confusão nas consoantes e os de confusão nas vogais. Para a conceção das propostas didáticas, remetemo-nos ao quadro teórico do interacionismo sociodiscursivo, na sua vertente de ensino de escrita através de género de texto. Para o presente trabalho, utilizámos o género resumo escolar.

PALAVRAS-CHAVE: Erros ortográficos; Género resumo escolar; Interacionismo sociodiscursivo; Produção escrita.

\section{Introdução}

Em Angola, o Português tem o estatuto de Língua Oficial, serve de instrumento de comunicação no país e é falado em todas as províncias, fundamentalmente, nos centros urbanos. É utilizado no sistema de ensino, desde a iniciação até ao ensino superior, e na

\footnotetext{
* Professor Assistente no Departamento de Línguas e Literaturas em Língua Francesa, na Faculdade de Letras da Universidade Agostinho Neto (Angola) e investigador no Centro de Linguística da Universidade NOVA de Lisboa (CLUNL). Mestre em Ensino da Língua Portuguesa e Doutorando em Linguística e Ensino de Língua. Desenvolve investigação no domínio do Ensino das Línguas Materna e Estrangeira pela Universidade Nova de Lisboa.
} 
administração pública. À semelhança do que acontece em outros países africanos da Comunidade dos Países de Língua Portuguesa (CPLP), a Língua Portuguesa (doravante, LP) tem vindo a sofrer inúmeras alterações relativamente à norma-padrão que lhe serve de referência. É também verdade que os jovens, sobretudo, luandenses e aqueles que vivem em zonas urbanas, têm uma certa competência na expressão oral, pois que o Português, para eles, é Língua Materna, salvo casos excecionais. No entanto, nota-se um grande distanciamento destas duas competências linguísticas: a expressão oral e a expressão escrita. Num dos seus artigos, Gomes (1990) escreveu:

As falhas ortográficas são uma das marcas /.../ que mais contribuem para o descrédito de quem as dá. Por muita formação que alguém tenha, por mais culto que seja, por mais poder de que disponha, um documento escrito, da sua responsabilidade, em que apareçam erros ortográficos é o suficiente para o desacreditar.

Na nossa atividade docente, na Faculdade de Ciências Sociais (doravante, FCS), temos estado a verificar que os estudantes apresentam imensas dificuldades no que diz respeito à produção textual e à ortografia. Após uma observação atenta dos programas de português do subsistema de ensino geral (básico e secundário), constatámos a inexistência de métodos didáticos específicos para o ensino de escrita. Diante deste cenário, nós concebemos o presente projeto que se consubstancia em quatro vertentes fundamentais:

- 1. estudar a situação sociolinguística de cada um dos estudantes e determinar in loco o grau de dificuldades que possui em termos de ortografia e produção textual; 2. aferir o nível de habilidades relativamente às atividades de leitura e de escrita; 3. determinar as causas que estão na base destas dificuldades, uma vez que os alunos falam, estudam e usam o Português no seu dia-a-dia; 4. propor soluções pedagógicas para o ensino de escrita e de produção textual (PT).

Para melhor alcançarmos os objetivos preconizados, nós optámos pela utilização do inquérito e observação direta como métodos de investigação. O inquérito serviu para recolhermos os dados inerentes à identificação pessoal, à situação sociolinguística e o grau 
de realização individual das atividades de escrita e de leitura. Por fim, solicitámos aos inquiridos que redigissem um texto de aproximadamente uma página, com o tema de sua preferência. A observação direta foi feita no momento da correção dos textos para podermos detetar os erros ortográficos e analisar os aspetos de coerência e coesão textuais. Foi utilizada uma amostra da população-alvo composta por 50 alunos de cinco turmas do $1^{\circ}$ Ano do curso de Gestão e Administração Pública, na razão de 10 para cada, retirados de forma aleatória.

O presente artigo consta de uma introdução, o corpo de trabalho, uma conclusão e as referências bibliográficas. O corpo de trabalho, por sua vez, está subdividido em quatro partes seguintes: 1. enquadramento teórico do tema, com abordagem aos conceitos de escrita; de erro ortográfico e sua classificação, e do interacionismo sociodiscursivo (ISD) de Bronckart, Dolz e Chneuvly (2007). 2. Situação sociolinguística da população discente, com destaque ao domínio linguístico e à identificação pessoal. 3. Identificação dos erros ortográficos, sua categorização e causas, e análise dos textos produzidos; 4. Os instrumentos didáticos de remediação, com realce ao modelo didático do género (MDG), seguido das sequências didáticas (SD).

\section{Enquadramento teórico: a escrita, o erro ortográfico e interacionismo sociodiscur- sivo}

Uma abordagem em torno da escrita implica, a princípio, uma análise, ainda que breve, sobre o que é a escrita, tanto mais que Niza (2011) e outros, no seu Guião de implementação do programa de português do ensino básico, consideram que a aprendizagem de escrita "constitui uma via de redescoberta e de reconstrução da língua", o que deixa antever que a escrita é uma atividade linguística e cognitiva. Reuter (1997), no seu livro intitulado Enseigner et apprendre à écrire, definiu a escrita nos seguintes termos:

une pratique sociale, historiquement construite, impliquant la mise en œuvre généralement conflictuelle de savoirs, de représentations, de valeurs, d'investissement et d'opérations, par laquelle un ou plu- 
sieurs sujets visent à (re)produire du sens, linguistiquement structuré, à l'aide d'un outil, sur un support conservant durablement ou provisoirement de l'écrit, dans un espace socio-institutionnel donné ${ }^{6}$ (REUTER, 1997. p. 58).

Reis (2009), por sua vez, diz que a escrita é:

o resultado, dotado de significado e conforme à gramática da língua, de um processo de fixação linguística que convoca o conhecimento do sistema de representação gráfica adotado, bem como processos cognitivos e translinguísticos complexos (planificação, textualização, revisão, correção e reformulação do texto), uma escrita correta, multifuncional e tipologicamente diferenciada, numa relação com a língua que seja norteada pelo rigor e pela exigência de correção linguística (REIS, 2009. p. 16).

Nas aceções acima apresentadas, notámos que Reuter dá relevância às dimensões social e linguística ao passo que Reis evidencia mais o fator linguístico, os processos cognitivos e translinguísticos complexos. Para o presente trabalho, que será embasado na teoria do ISD, vamos interligar os dois conceitos: o aspeto social e linguístico, pois que a valorização da dimensão social insere-se pelo facto daquilo que Coutinho descreveu "ensinar a escrever é ensinar a agir socialmente, e desenvolver uma tal capacidade implicará a identificação das características contextuais e organizacionais que a configura" (COUTINHO, 2012. p. 11).

Para desenvolvermos a noção do "erro ortográfico", julgamos conveniente partir das definições de "erro" e de "ortografia". Etimologicamente, "erro" é uma derivação regressiva de "errar". Provém do latim errare, que significa fazer de forma incorreta. No âmbito do presente estudo, errar será proceder fora das regras oficialmente estabelecidas na utilização do Português Europeu, de acordo com a norma escrita resultante dos Acordos Ortográficos de 1945, ainda em vigor em Angola. A palavra 'ortografia' vem do grego,

\footnotetext{
${ }^{6}$ uma prática social, historicamente construída, envolvendo uma implementação geralmente conflituosa de conhecimentos, de representações, de valores, de investimentos e de operações, na qual um ou mais sujeitos visam (re) produzir o sentido, linguisticamente estruturado, usando uma ferramenta, num meio em que possa preservar de forma duradoura ou temporária a palavra escrita e num dado espaço socioinstitucional (tradução nossa).
} 
orthós e graphos. Orthós que significa "correta" e graphos quer dizer "escrita". Logo, quando falamos de ortografia referimo-nos à escrita correta, a arte e modo de escrever (ou que ensina a escrever) corretamente as palavras de uma língua. Atualmente, não notamos grandes alterações na evolução semântica de vocábulo "ortografia”. Vejamos, de seguida, as definições extraídas dos livros especializados. No Dicionário de Metalinguagem da Didática, consta "a ortografia é um sistema de escrita de uma língua composto por grafismos convencionais. Este sistema gráfico representa de um modo convencional o sistema fónico". O Dicionário da língua portuguesa contemporânea da Academia de Ciências de Lisboa apresenta a seguinte aceção "a ortografia é uma maneira correta de escrever as palavras de uma língua de acordo com uma determinada norma”. Tendo em consideração os conceitos acima apresentados, diremos que o erro ortográfico será, obviamente, a maneira de escrever as palavras portuguesas fora das normas ortográficas do Português-padrão. Portanto, a ortografia é artificial, convencional, imposta, ao contrário da língua oral que é natural; e a escrita é uma representação gráfica da língua falada. Como nenhuma ortografia consegue reproduzir a fala com fidelidade e, logo, aqui começam os problemas.

Ao cingir-nos aos erros ortográficos, baseamo-nos na taxionomia obtida pela sistematização de cinco macrocategorias (ou tipos), subdivididas em onze microcategorias (ou subtipos) apresentada por Gomes (2006) no seu livro intitulado Ortografia para todos. Eis a classificação: i. erros resultantes da não correspondência entre o som e grafema - omissão ou adjunção de vogais ou de consoantes, confusão nas vogais ou nas consoantes, inversão de vogais ou de consoantes; ii. erros de morfossintaxe - a nível morfemático e a nível lexemático; iii. erros de acentuação - omissão ou adjunção de acentos, confusão (de sinais), deslocação (da sílaba tónica); iv. erros de pontuação - omissão dos sinais de pontuação, confusão nos sinais de pontuação; v. erros semânticos-pragmáticos. No âmbito da delimitação do nosso trabalho, e tendo em conta a sua natureza investigativa, limitámo-nos a trabalhar nas primeiras três macrocategorias e nos outros erros de natureza similar, não apresentados por Gomes (2006), mas que foram detetados. 
A nossa pesquisa tem como basse teórica o interacionismo sociodiscursivo (doravante, ISD) na sua perspetiva de intervenção no ensino das línguas, particularmente, de escrita, que é o nosso propósito. Segundo Bronckart (1996), o ISD é um quadro teórico e epistemológico que se inscreve no âmbito do interacionismo social, preconizando uma ciência integrada do humano, que possa dar conta da interdependência entre aspetos sociais, psicológicos e linguísticos, e focalizando o papel decisivo da linguagem na constituição do pensamento consciente e no desenvolvimento da pessoa desde o nascimento até à morte. O texto é, assim, entendido como portador de sentido, materializado e construído sóciohistoricamente. Por sua vez, o discurso deve ser entendido como prática e/ou processo de linguagem. Deste ponto de vista, acreditamos que o ISD, como quadro teórico, fornece um instrumental didático pertinente para concretizar os objetivos do ensino/aprendizagem da LP em Angola, mais concretamente na vertente da escrita. Assim, resultaria numa melhor eficácia quanto ao desenvolvimento da competência escrita nos estudantes do ensino superior. Nesta linha teórica, pretendemos elaborar materiais didáticos, com foco nos discentes (e, também, nos docentes), que possam favorecer a aquisição das capacidades de uso da língua, principalmente, dos géneros textuais que dominam a vida cotidiana e subsidiam o trabalho de produção e compreensão de textos escritos. Tratando-se do domínio de escrita, sobretudo em contexto escolar e no nível superior, o nosso trabalho vai incidir, não somente aos erros ortográficos, mas também aos aspetos ligados à produção textual, numa lógica de géneros. A nossa escolha a esta linha de investigação foi feita tendo em consideração a outras qualificações e atribuições do ISD feitas por Bronckart (2004), a saber: i. uma ciência (permanente) sustentada pela reflexão epistemológica (suscetível de repensar modelos e dados); ii. uma ciência interventiva (capaz de medir a validade do conhecimento que produz pela capacidade de transformação ou de operacionalização prática); iii. uma ciência natural (que rejeita a oposição entre ciências naturais e ciências humanas) - em função da adesão aos princípios de monismo materialista e de paralelismo psicofisiológico, 
herdados de Spinoza. Desse modo, a perspetiva interativa sociodiscursiva na qual se inscreve o nosso estudo no âmbito da didática da língua materna ${ }^{7}$ permitirá considerar uma redefinição da interação professor-aluno, com especial ênfase no papel essencial a ser desempenhado por uma destas entidades e a reciprocidade de atuação/agir. Possibilitará, ainda, sensibilizar e ajudar os alunos a semiotizar as suas representações a fim de estruturar os seus conhecimentos e as suas experiências que os levarão a reproduzir, numa determinada situação social, os processos sociocognitivos já existentes no meio natural, os quais não constituem fenómenos estranhos para o estudante.

\section{Situação sociolinguística dos estudantes}

A existência de várias sociedades, várias culturas e, consequentemente, várias línguas em Angola faz com que certos aprendentes não tenham o Português como língua materna, embora seja ele Língua Oficial e falada em território nacional, particularmente, nas cidades capitais das províncias. Para se determinar a situação sociolinguística dos informantes, procuramos saber a idade, a naturalidade, o meio vivencial, a profissão e as línguas que fala (a materna, a de uso corrente, a segunda e, eventualmente, as estrangeiras). A este respeito, nós constatámos que a maior parte dos estudantes (92\%) é jovem, com menos de 40 anos e a idade mínima é de 20 anos. Isto é positivo, pois demonstra que os estudantes possuem ainda as suas habilidades cognitivas e sensoriais que são indispensáveis no processo de ensino/aprendizagem; 88\% nasceu num meio urbano e quase todos (92\%) viveram igualmente em centros urbanos onde predomina a LP; todos possuem profissões ou atividades diárias nas quais utilizam o Português como língua de trabalho. No domínio linguístico, todos (100\%) utilizam a LP no seu quotidiano; $72 \%$ possui o Português como língua materna e somente um quarto fala mais ou menos bem uma língua estrangeira ${ }^{8}$. Com

\footnotetext{
${ }^{7} \mathrm{O}$ estudo foi enquadrado no domínio da língua materna em função dos resultados obtidos na primeira fase da pesquisa, sobre a situação sociolinguística dos alunos, no qual, apurou-se que $72 \%$ tem o português como língua materna.
}

${ }^{8}$ Esta informação foi recolhida nos inquéritos e não nos foi possível aferir a sua veracidade. 
estes dados, reduzimos as hipóteses de haver interferência de outras línguas no Português falado por esta população estudantil. E mais, uma parte de estudantes tem pais bilingues (falam Português e língua nacional), exibe um comportamento linguístico criativo, com capacidade de produzir e compreender formas e estruturas que nunca antes ouvidas (MADEIRA, 2017, p. 308).

\section{Erros ortográficos dos alunos: classificação e causas. Atividades de leitura e de es- crita. Produção textual.}

É evidente que a identificação e classificação dos erros ortográficos comporte várias dificuldades, dadas as possibilidades que, frequentemente, se nos apresentam quando confrontados com aspetos de produção textual. Por esse motivo, ao classificar o tipo de erro presente numa determinada sequência tornou-se essencial tentar perceber o significado que o estudante atribuiu em função da mensagem que pretendeu transmitir. Assim, depois de identificados os desvios, procedermos à sua reconstrução na norma-padrão. Após os trabalhos sobre a identificação e classificação linguística dos erros, chegámos às seguintes conclusões:

- quanto à identificação dos erros, os mais frequentes são: $a$ (por à), tenhem (por têm), e (por é), a (por há), ha (por há), varias (por várias), ja (por já), esta (por está), tambem (por também), proprios (por próprios); nivel (por nível), politico (por político), mais (por mas) e familia (por família). Os menos frequentes são: ate (por até), deliquencia (por delinquência), alguem (por alguém), a cusação (por acusação), soledariedade (por solidariedade), semper (por sempre) e distacar (por destacar). Feita a classificação linguística, constatámos que os erros de omissão de acentos, os de confusão nas consoantes e os de confusão nas vogais são os mais abundantes, com 26, 15 e 14\% respetivamente; e os menos identificados são os erros de inversão de vogais ou de consoantes; os de deslocação da sílaba tónica e os de morfossintaxe a nível lexemático, que nem sequer atingiram $01 \%$. 
Relativamente às causas, e segundo Gargallo (2004), a explicação dos problemas verificados na aprendizagem de uma língua (de modo geral) afigura-se de grande utilidade, pois fornece dados importantes que permitem obter um melhor conhecimento acerca desse processo, o que, do ponto de vista de ensino, poderá ser extremamente útil na definição das estratégias e na produção de materiais a utilizar em contexto formal. Contudo, sucede com frequência não ser possível determinar com exatidão as causas dos erros em virtude da sua complexidade e da multiplicidade de hipóteses que poderão estar na sua origem. Deste modo, procurámos fazer uma abordagem de forma abrangente, na opinião dos autores que consultámos, sendo eles peritos na matéria, e de acordo com as informações fornecidas pelos próprios estudantes através do inquérito. Falámos ainda das causas com base nas nossas experiências profissionais de mais de vinte anos de serviço no ensino secundário e, mais tarde, no superior. Falar de erros ortográficos é falar de dificuldade de aprendizagem, em geral, o que remete para plurais fatores nem sempre fáceis de equacionar. Cada aluno é um caso e deve ser cuidadosamente observado, despistando fragilidades que uma análise menos atenta seria incapaz de detetar. No seu livro intitulado "Ortografia para todos. Para (ensinar a) escrever sem erros", Gomes (2006) escreveu o seguinte:

inumeráveis são os fatores que contribuem para que um aluno erre. Se limitarmos, neste contexto, o conceito de "erro" ao "erro ortográfico”, ainda assim múltiplas são essas causas. Bastar-nos-ia, para nos darmos conta da complexidade da situação, lembrar os fatores relacionados com: aspetos psicológicos: memória, atenção, perceção...; métodos de leitura seguidos; o meio social do aluno: (pobreza do) vocabulário usado; hábitos de leitura...; um grande contacto com situações predominantemente orais - conversação, audiovisuais...; dificuldades da própria língua; interferências linguísticas. (GOMES, 2006, p. 58)

Fonseca (1994), debruçando-se sobre algumas dessas dificuldades (de aprendizagem), reconhece que “os fatores de desenvolvimento humano não são imutáveis, pois há neles uma multiplicidade de interações dinâmicas". E apresenta uma síntese que engloba aspetos psicológicos (percetivos, cognitivos, psicomotores, emocionais, ...) e aspetos sociológicos que têm a ver com as condições sociais: nutricionais, habitacionais, materiais, etc. 
Costa (1992), na sua comunicação, com o título "A concę̧ão eurocêntrica do universo linguístico em Angola e as suas consequências nocivas na difusão da Lingua Portuguesa" valoriza a influência das línguas locais em coabitação com a LP. Segundo ele, esta convivência dá lugar a uma variante sociolinguística, configurada pelo sistema lexical português, por um lado, e pelo sistema lógico-sintático das línguas bantu por outro. Já Galisson (1980) valoriza a influência da língua materna da criança, nos casos em que o Português é língua segunda. No seu livro intitulado Du structuralisme au fonctionnalisme refere ele que, na aprendizagem de uma língua segunda, algumas causas se podem destacar:

On cherche donc ses origines du côté de la langue maternelle de l'apprenant, mais aussi de sa stratégie d'apprentissage (utilisation trop ou pas assez systématique de la généralisation, de l'analogie, etc.) et même de la méthode d'enseignement utilisée, ce qui met en jeu la responsabilité de l'enseignant ${ }^{9}$. (GALISSON, 1980, p. 67)

Vital e Crispin (1999), no seu artigo intitulado "Aquisição da linguagem escrita: conbecer para intervir", citam Da Silva e Zorzi. Estes afirmam que "a oralidade e a escrita fazem parte de um mesmo processo cognitivo, onde um tipo de conhecimento dá origem a outro, fazendo com que durante um certo período, os conhecimentos da linguagem oral sejam empregados como instrumentos de assimilação da escrita”. E, Oliveira (2009), debruçando-se sobre a matéria afirma:

o problema residirá, sim, nos alunos quando os professores constatarem o fracasso escolar de origem psicológica, tal como os problemas emocionais (por estarem sempre distraídos, não conseguirem se concentrar), quando erram ao falar, quando não entendem o que o professor explica, podendo revelar preguiça, rebeldia e desinteresse pelos estudos. (OLIVEIRA, 2009, p. 51)

$\mathrm{Na}$ aprendizagem da ortografia em contexto escolar, a criança é influenciada pelo meio, pois se ela puder expressar-se bem, vai igualmente escrever bem. Por isso, existirá,

\footnotetext{
${ }^{9}$ Portanto, buscamos as suas causas a partir da língua materna do aluno, mas também da sua estratégia de aprendizagem (uso excessivo ou não sistemático da generalização, da analogia, etc.) e até mesmo do método de ensino usado, envolvendo, assim, a responsabilidade do professor. (Tradução nossa).
} 
sim, um processo mecânico que os professores usam para fazer assimilar as respetivas letras e os respetivos sons, fazendo entender tratar-se de uma transcrição da oralidade. Neste contexto, muitos didatas consideram os "erros" como sendo "distúrbios", como, por exemplo, quando as crianças trocam as letras por terem sons iguais "C", "Ç", "SS", "S", etc., nas palavras como “ćédula, calça, passo e bolśso". Neste contexto, é importante saber que os "erros" são um processo sequencial da aprendizagem da língua, pois, como o diz o pedagogo Vygotsky “a linguagem escrita é uma função linguística distinta, que difere da linguagem oral tanto pela sua estrutura quanto pela sua função. Até aos seus estágios mais elementares de desenvolvimento, exige um alto nível de abstração”.

Tendo em conta os problemas atrás evocados, podemos apontar como causas, as seguintes: 1. Contexto sociocultural (de forma genérica) - a existência de várias culturas e realidades sociais. 2. Contexto de aquisição (de forma específica) - embora tenham o português como língua materna, este, em alguns casos, foi adquirido em contexto bilingue (ou multilingue) dos pais e vai-se denotando a sistematicidade que caracteriza os erros produzidos ao longo do processo de aquisição e desenvolvimento deste Português LM (MADEIRA, 2017, p. 308). 3. Falta de funcionamento do grupo disciplinar - a falta de colaboração dos docentes de outras disciplinas para se poder encontrar soluções intradisciplinares e/ou interdisciplinares mais adequadas. 4. Má preparação anterior - desconhecimento das

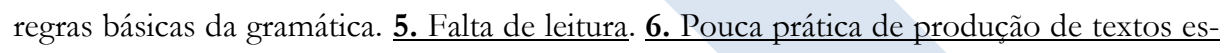

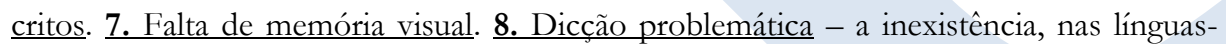
bantu, de determinados sons ou sequência de sons da LP dão lugar a erros fonéticos e, consequentemente, à escrita. 9. Pobreza vocabular. 10. Desconhecimento da formação das palavras. 11. Problemas de interferências linguísticas - engendrados pela coabitação da LP com as línguas locais.

Sobre as atividades de leitura e de escrita, os resultados não são favoráveis: 48\% escreve mais de cinco páginas por semana (esta percentagem inclui as páginas escritas durante as aulas, sem, no entanto, uma apreciação posterior por parte do docente, e não se trata de textos escritos em contexto extraescolar); 38\% lê mais de cinco jornais por semana 
e $04 \%$ lê mais de três livros por mês ${ }^{10}$. Entretanto, enquanto estudantes, as atividades de leitura e de escrita não são feitas de modos a permitir o melhoramento da ortografia.

\section{Produção textual}

Sendo essencial a coerência e coesão textuais para que a comunicação se estabeleça de forma eficaz entre quem produz e quem interpreta, quisemos centrar-nos na análise destes dois aspetos, tentando identificar os problemas que mais afetaram as produções dos alunos. A coerência é vista como elemento que confere um sentido ao texto. E, a coesão, o elemento responsável pela conexão de palavras, expressões ou frases dentro de uma sequência. Por uma questão de delimitação do tema, no que tange à coerência, fixámo-nos a analisar a relação lógica e harmónica entre as ideias, sua ordenação e interligação, formando, assim, uma unidade com as partes concatenadas. Ao analisarmos os textos, saltou-nos à vista, a ausência da tradicional estrutura tripartida dos textos (introdução, desenvolvimento e conclusão), na ordem dos $70 \%$. Os textos pareciam como "um amontoado de frases" que, dificilmente, se poderia distinguir de forma compreensível, as três partes indispensáveis na elaboração de um texto. Quanto à sua legibilidade e à compreensão da mensagem textual, não constatámos problemas relevantes. No que concerne à coesão, foi visível, a interfrásica, afetada na ordem dos 30\%. Em alguns casos, os conectores e marcadores discursivos que estabelecem relações de dependência entre os elementos que constituem uma frase ou sequência de frases não eram os mais indicados, como por exemplo, “... diziam que ela merecia um homem intelectual, então ela conheceu um jovem que era advogado,

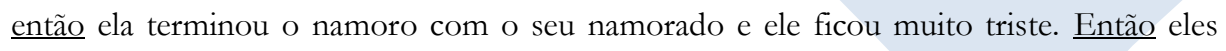
começaram a namorar /.../". Houve, no entanto, ao nível da coesão nominal, a utilização de forma adequada das anáforas pronominais, na maior parte dos textos, $90 \%$. Finalmente, a elaboração de rascunho, não foi tido como elemento importante na produção textual por parte dos alunos. Por enquanto outros alegaram não terem tempo suficiente para o fazer.

\footnotetext{
${ }^{10}$ Informação recolhida dos inquéritos.
} 


\section{Instrumentos de remediação: modelo didático do género e sequências didáticas}

Nesta parte do nosso trabalho, vamos apresentar os instrumentos didáticos que poderão auxiliar o docente na busca de soluções (de remediação) para os problemas identificados. Nós preferimos usar a expressão “remediação” para nos referirmos às soluções imediatas. Pois, trata-se de estudantes de ensino superior, alguns mesmo já com responsabilidades na sociedade. Para isso, remetemo-nos à teoria do ISD de Bronckart (e outros) que defende o ensino de escrita através dos géneros. Iremos conceber um modelo didático de género e, consequentemente, as sequências didáticas (SD). A problemática dos géneros, bem como os tipos de textos, assume uma particular relevância no ensino de escrita ao nível de ensino superior, tal como advoga Coutinho « une des stratégies possibles, en vue d'une amélioration de l'écriture du savoir, dans le supérieur, sera donc liée à une conscience plus développée de la tâche elle-même - c'est-à-dire au développement de la conscience des enjeux discursives et textuels $»^{11}$ (COUTINHO, 2002. p. 180).

\section{Modelo didático de género}

Segundo De Pietro et al. (1996), o modelo didático de género (MDG) é um objeto descritivo e operacional construído para apreender o fenómeno complexo da aprendizagem de um género e orientar as atividades escolares. O MDG aponta os aspetos fundamentais a serem trabalhados, com base em uma análise prévia de um ou mais texto(s) pertencente(s) a um determinado género (SCHNEUWLY E DOLZ, 1998. p. 100). Este, sendo objeto descritivo e operacional, evidencia as dimensões ensináveis, a partir das quais as SD serão concebidas (SCHNEUWLY E DOLZ, 2004. p. 63). Entende-se por SD, o conjunto de atividades organizadas de maneira sistemática, em torno de um género textual oral ou escrito (SCHNEUWLY E DOLZ, 2004. p. 97). Para o assunto em estudo, nós retivemos o género resumo escolar, e, por ser um texto resultante da sintetização de um outro texto,

\footnotetext{
11 "uma das estratégias possíveis a fim de melhorar a escrita de conhecimento, no superior, será, portanto, vinculada a uma consciência mais desenvolvida da tarefa em si, isto é, ao desenvolvimento da consciência no que tange às questões discursivas e textuais". (tradução nossa)
} 
descartamos a possibilidade de efetuar uma análise detalhada do texto-fonte. Limitamo-nos a analisar aspetos importantes na abordagem desta temática, com destaque ao contexto de produção (contexto físico, social e subjetivo), a infraestrutura geral (plano de texto e tipo de discurso) e as coesões verbal e temporal.

Tabela 1. Contexto de produção

\begin{tabular}{|l|l|}
\hline \multicolumn{2}{|c|}{ Contexto físico } \\
\hline Local de produção & Luanda, Angola \\
\hline Momento de produção & 1987 \\
\hline Emissor & Boa Ventura Cardoso \\
\hline Recetor & Público em geral \\
\hline \multicolumn{2}{|c|}{ Contexto social e subjetivo } \\
\hline Espaço social & Meios urbano e social \\
\hline Posição social do emissor & Escritor e governante angolano. \\
\hline Posição social do recetor & $\begin{array}{l}\text { Indivíduos anónimos, à mercê do emissor e socialmente isolados. } \\
\text { Cada um com as suas características socio-estruturais, culturais, } \\
\text { grau de instrução, classe social, profissão, faixa etária, género, etc. }\end{array}$ \\
\hline Objetivo da interação & $\begin{array}{l}\text { Publicar textos por si produzidos que possam ser lidos pelos } \\
\text { membros da sociedade. }\end{array}$ \\
\hline
\end{tabular}

No que concerne à infraestrutura geral do texto, analisámos o tipo de discurso e o plano de texto, que é a organização global do conteúdo temático, podendo ser identificado no momento de leitura e apresentado de forma codificada numa espécie de resumo.

Tabela 2. Plano de texto

\begin{tabular}{|r|l|}
\hline \multicolumn{1}{|c|}{ Parágrafos } & \multicolumn{1}{c|}{ Plano de texto } \\
\hline 1 & - Saído do cinema noturno, o narrador andava isolado e medonho. \\
\hline 2 & $\begin{array}{l}\text { - O silêncio foi cortado com barrulho de cães, gatos, cabaças; de assobios e vo- } \\
\text { zes de invisíveis que saía da árvore que, mais tarde, esbofetearam-no até cair } \\
\text { no desmaio, }\end{array}$ \\
\hline 3 & - Tentativa de derrubar a árvore pelos caminhantes. \\
\hline 4 & - Apresentação das particularidades mitológicas e milagrosas da árvore. \\
\hline
\end{tabular}


No que tange ao aspecto discursivo do texto como processo semiótico que, no seu fluxo sintático, vai produzindo sentido, analisámos as suas características e a forma como hierarquicamente se encontram organizadas as partes textuais. Segundo Bornckart (1996), os tipos de discurso são formas linguísticas alicerçadas nos textos e traduzindo a criação de mundos discursivos específicos. Ao observarmos o texto "A árvore que tinha batucada", verificámos que a descrição aparece em doses muito menores. Não se notam características conversacionais, explicativas, argumentativas nem instrucionais. Mas sim, sequências (discursivas) que representam um conjunto de eventos organizados entre si e protagonizados por uma personagem principal (que é o próprio narrador) e outras secundárias (os caminhantes, os mais velhos), situadas num determinado espaço e tempo. Desta forma, concluímos que o texto é predominantemente narrativo, composto por unidades de base (orações) que são o produto de atos de enunciação bifaciais: são ao mesmo tempo microunidades sintáticas e microunidades semânticas. Estas, por sua vez, formam as macrounidades que são as partes maiores que constituem o texto, tal como afirma Adam (2017):

le modèle de la séquence narrative de base a pour but d'expliciter cette observation essentielle en définissant ce qui assure le lien des propositions ainsi que leur empaquetage sous forme de macro-propositions constitutives d'une séquence elle-même partie d'un texte ${ }^{12}$. (ADAM, 2017, p. 117).

\section{Sequências didáticas}

$\mathrm{Na}$ nossa atividade docente, temos notado com frequência uma dificuldade incrível nos estudantes em sintetizar as ideias. O facto, é que este tipo de atividade raramente é explicado durante as aulas, mas que são solicitadas com regularidade. Em contexto escolar, o resumo será simplesmente informar sobre o que é mais importante em um determinado texto. Não incorporará comentários ou julgamentos nem será uma crítica ou resenha. A

\footnotetext{
${ }^{12} \mathrm{O}$ modelo da sequência narrativa de base tem como objetivo tornar explícita esta observação essencial, determinando o que liga as orações em frases constitutivas de uma sequência que é, pois, parte de um texto. (tradução nossa).
} 
presente SD consistirá em propor um conjunto de atividades que possam possibilitar o desenvolvimento das capacidades de linguagem necessárias para a produção de textos. Ela deverá englobar as práticas de escrita para que o aluno possa realmente apropriar-se delas, permitindo-lhe escrever de maneira mais adequada em determinada situação de comunicação. A SD será composta de: i. apresentação da situação, que consiste na descrição da tarefa - o momento em que se constrói, com os alunos, a representação sobre a situação de comunicação e a atividade de linguagem a ser executada; ii. produção inicial - os alunos são solicitados a resumir um texto, fornecido pelo professor, a partir das explicações anteriores (com a função diagnóstica); iii. realização de oficinas - os alunos realizam diferentes atividades e exercícios direcionados para o objetivo global, seguidos de uma ficha informativa; iv. produção final - ouvidos os respetivos esclarecimentos sobre o assunto, esta última redação irá possibilitar os alunos a aplicação dos conhecimentos adquiridos e uma reflexão acerca da sua evolução ao longo da SD.

Tratando-se de elaboração de um resumo escolar, através da operacionalização de oficinas de escrita, propomos o modelo de preparação seguinte: 1 . Assunto: produção de resumo do texto: A árvore que tinha batucada, de Boa Ventura Cardoso (ver anexo 1). $\underline{2}$.

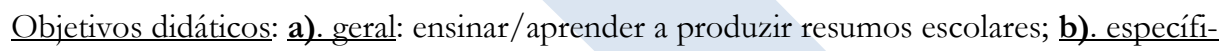
$\underline{\text { cos: }}$ perceber as informações textualmente relevantes; reconhecer os meios linguísticos utilizados nas diferentes partes do texto; destacar os meios linguísticos utilizados na construção da coesão textual (p. ex: conectores); detetar as ideias principais e secundárias do texto; proceder à produção textual, observando as fases de planificação, textualização e revisão; saber realizar as operações de construção da coesão e coerência textuais; saber escrever (e expressar-se) com correção linguística. 3. Conteúdos: estruturação da atividade da produção textual em três etapas: planificação, textualização (redação) e revisão (com a correção); resumo de um texto narrativo; funcionamento da língua - mecanismos de coerência e coesão textuais: referentes e conectores. 4. Padrões de interação: fornecimento de instruções relativas à elaboração de um resumo por parte do professor; diálogo interativo: professor - alunos e alunos - alunos; trabalho individual para produção do resumo inicial; trabalho 
de grupo para aplicação das instruções relativas à produção de um resumo, em função das instruções dadas; trabalho conjunto de produção de um resumo cooperativo; monitorização do trabalho dos alunos feita pelo professor ou pelos alunos mas com a orientação do docente; revisão dos textos produzidos pelo coletivo; trabalho individual para produção de

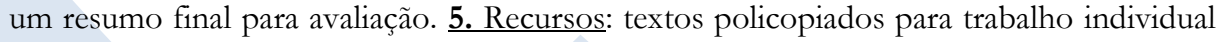
e/ou de grupo; acetato para produção de um resumo coletivo e retroprojetor (se possível, melhor); ficha informativa que espelhe as regras a considerar na elaboração do resumo. $\underline{\mathbf{6}}$. Avaliação: formativa - observação direta e repetida do trabalho, na aula, para apurar a participação de cada aluno; grelha de observação para avaliação da produção final dos alunos (concebida pelo professor em função dos aspetos tratados).

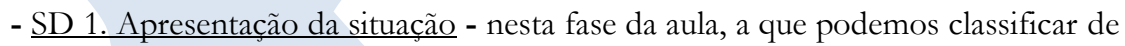
introdutória, o professor faz a descrição da tarefa, ou seja, procura construir, com os alunos, a representação sobre a situação de comunicação e as atividades a serem executadas Professor: "vamos resumir o texto que têm em mãos" (ver anexo 1). "De que texto se trata?”; "Quem é o seu autor?"; "têm lido as suas obras ou outras similares?”; "Leiam-no atentamente e tentem condensar a informação que o texto dá, quer dizer, separando o que é secundário e manter apenas as ideias principais (o essencial) para que a ideia seja entendida (=resumo) ".

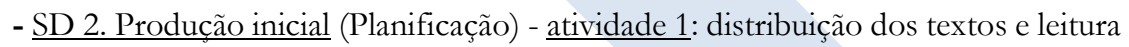
silenciosa. - Atividade 2: leitura analítica e crítica, procurando identificar: o género do texto, com a devida justificação; o meio de circulação; as ideias principais e as ideias secundárias; a data e local de publicação; as condicionantes passivas da leitura (o título, o tema, se é extrato de uma obra ou não) e uma breve abordagem sobre o autor do texto. Atividade 3 : elaboração de resumo do texto, feito individualmente.

N.B: a realização das oficinas de aprendizagem de caráter formativo, constituídas por um conjunto de atividades que pretendem trabalhar os problemas detetados inicialmente, fornecem aos alunos os instrumentos essenciais ao domínio do género em estudo. Nesta fase, com a ajuda do professor e dos colegas (em interação) o aluno deve considerar 
o seu texto como objeto de estudo, observando, manipulando e analisando o material linguístico. Aqui os alunos realizam diferentes atividades e exercícios direcionados para o objetivo global, seguidas de ficha informativa. (ver anexo 2)

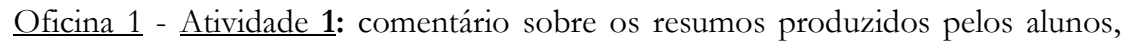
destacando os aspetos positivos e negativos, em interação - professor - alunos. Atividade 2: reflexão em torno daquilo que os alunos consideraram mais difícil para a resolução da tarefa proposta na fase anterior. Atividade 3: explicitação dos problemas detetados. Atividade 4: extração das ideias mais relevantes do texto, sempre em interação com o professor e, os alunos, por sua vez, entre si. Atividade 5: esclarecimentos, por parte do professor dos princípios básicos, da linguagem e dos procedimentos a seguir.

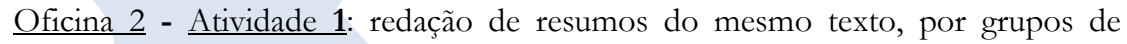
dois/três alunos, tentando pôr em prática as explicações dadas. Atividade 2: leitura dos resumos elaborados e distribuídos pelo professor, e assinalar o que acreditam ser o melhor. Atividade 3: sublinhar as alternativas que justifiquem a escolha do melhor resumo: a) correção gramatical e léxico adequado à situação escolar; b) seleção das informações consideradas importantes pelo leitor, que são os autores do resumo; c) seleção das informações colocadas como as mais importantes do texto-fonte; d) o resumo permite que o professor avalie a compreensão do texto lido, incluindo a compreensão global, o desenvolvimento das ideias e a articulação entre elas; e) apresentação das ideias principais do texto e das suas relações; f) existência de comentários pessoais associados às ideias do texto. Atividade 4 : discussão sobre as opiniões dos alunos que culminará com o estabelecimento das regras de elaboração de um resumo.

Oficina 3 (Textualização) - Atividade 1: identificação das ideias principais de cada um dos parágrafos ou partes do texto-fonte. Atividade 2: sublinhar as palavras/expressões que marcam a rede semântica do texto-fonte. Atividade 3: levantamento dos conectores discursivos para a articulação da informação. Atividade 4: redação do resumo em grupo de dois/três, se possível em acetato, em função das regras estabelecidas na atividade anterior. 
Oficina 4 (Revisão) - Atividade 1: correção e debate sobre os resumos elaborados. Aqui o professor corrige os erros ortográficos previamente recolhidos, os aspetos relacionados com a elaboração de resumo e aproveita tirar todas as dúvidas possíveis. Atividade 2: construção de um resumo coletivo, aplicando todas as noções aprendidas, se possível, feita em acetato.

NB: terminada a realização das oficinas e se o professor fizer um prognóstico positivo dos objetivos didáticos preconizados, dá a possibilidade aos alunos de aplicarem os conhecimentos ora adquiridos e de refletirem acerca da sua evolução ao longo da SD.

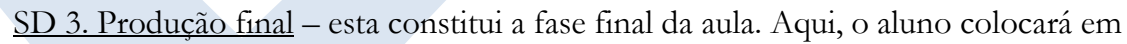
prática todos os conhecimentos adquiridos e, juntamente com o professor, avaliará a evolução alcançada. Atividade 1: produção do resumo final feita individualmente, aplicando as regras básicas aprendidas de elaboração de resumo. Esta pode ser sujeita à avaliação formativa. Atividade 2 (avaliação): elaboração de resumo de um outro texto que pode ser do mesmo autor ou não.

OBS: para o tratamento dos erros ortográficos, nós propomos algumas técnicas de correção, dentre as várias existentes: i. correção feita na sala numa aula própria (em oficina de escrita), em grupo, fazendo comentários magistrais; ii. o professor deve antes verificar as hipóteses feitas pelo aluno e a origem do erro e, posteriormente, dar indícios suficientes que permitam os estudantes corrigirem eles próprios os seus erros; iii. o professor utiliza os erros como uma ilustração para explicações na aula.

\section{Considerações finais}

Neste artigo, procurámos estudar a problemática da escrita no Ensino Superior em Angola, que é um problema estrutural no seio da população discente, a nível nacional. Esta realidade constitui uma das maiores preocupações do Ministério do Ensino Superior angolano na medida em que tende a baixar, em certa medida, a qualidade dos formandos. Por este motivo, concebemos o presente projeto que teve como objetivos, identificar in loco os erros cometidos por estes aprendentes, determinar as suas causas e propor instrumentos 
didáticos para se encontrar as soluções de remediação. Ao longo dos trabalhos, quisemos saber também da situação sociolinguística dos alunos, sendo Angola, um país multilíngue.

Feita a recolha e a análise dos dados, chegámos às seguintes conclusões: 1. no domínio linguístico, todos os estudantes utilizam o Português no seu cotidiano; 2. os erros de omissão de acentos, de confusão de consoantes e os de confusão de vogais são os mais abundantes; 3. as causas prendem-se fundamentalmente com os problemas ligados aos contextos de aquisição (especificamente) e sociocultural, às questões de interferência linguística, à má preparação anterior, à falta de leitura, à pouca prática de produção textual, ao desconhecimento da formação das palavras, etc. 4. Quanto à organização sequencial dos textos, destaca-se a ausência da tradicional estrutura tripartida na ordem dos $70 \%$ e a coesão interfrásica que foi afetada na ordem dos 30\%. As anáforas pronominais foram utilizadas de forma adequada e a elaboração de rascunho não foi tido como elemento importante. As atividades de leitura e de escrita devem ser imperativamente incentivadas, pois que ajudam a melhorar a ortografia. Para fazer face às situações acima mencionadas, apresentámos os instrumentos didáticos, como proposta, embasados no MDG e SD alicerçados na teoria do ISD de JP Bronckart e alguns procedimentos didáticos para a correção dos erros.

Por último, nós propomos que na elaboração de programas de ensino deve-se ter em consideração as diversas realidades e culturas vigentes em Angola, conforme advoga o Costa (1992) "um projeto mais englobante e verdadeiramente atualizado, que tenha em conta a real dimensão da componente sociolinguística nacional e que não se erga contra a natura".

\section{LES PROBLEMES D'ECRITURE DANS L'ENSEIGNEMENT SUPERIEURE EN ANGOLA : DES OUTILS DE REMEDIATION}

RESUME : notre article fait un abordage sur le problème de l'écriture, et plus particulièrement, les fautes d'orthographe des étudiants de la Faculté des Sciences Sociales de Luanda - Angola. Notre objectif est de développer leur compétence écrite et celle de la production textuelle. Pour ce faire, nous avons jugé utile identifier et classifier d'abord les erreurs commises dans leurs textes. Ensuite, nous avons présenté les causes qui sont à la base de ce handicap et, finalement, nous avons proposé des outils didactiques qui peuvent être utilisés par les enseignants pour trouver des solutions de re- 
médiation. Ce travail ne servirait qu'à aider les apprenants à améliorer leur expression écrite et, conséquemment, leurs habiletés concernant la production textuelle. La cohabitation en Angola de la langue portugaise avec des langues nationales (kikongo, kimbundu, umbundu, etc.) nous a amenés à déterminer également la situation sociolinguistique de chacun des élèves, avant de mettre en œuvre le projet. Pour recueillir les données, nous avons utilisé une enquête, et dans laquelle, on a demandé que chacun produise un texte. Après avoir analysé des données, nous avons constaté que les erreurs les plus fréquentes étaient celles d'omission d'accents, celles de confusion des consonnes et celles de confusions de voyelles. Finalement, nous avons proposé des outils didactiques sur la base de la théorie d'interactionnisme socio-discursif, plus précisément dans son domaine de l'enseignement de l'écriture à travers le genre du texte. Et, comme genre, nous avons utilisé le résumé scolaire.

MOTS-CLÉS : Erreurs orthographiques ; Résumé scolaire ; Interactionnisme socio-discursif ; Production écrite.

\section{REFERÊNCIAS}

ASTOLFI, Jean-Pierre. Le statut de l'erreur dans l'apprentissage. ESF Editeur. Paris, 2001.

BARBEIRO, Luís Filipe. Os alunos e a expressão escrita. Fundação Calouste Gulbenkian. Lisboa. 1999.

BRONCKART, J. P. Activité langagière, textes et discours. Pour un interactionnisme socio-discursif. Éditions Delachaux et Niestlé. Lausanne, 1996.

BRONCKART, J. P. La médiation langagière, son statut et ses niveaux de réalisation. In R. Delamotte et al., Les médiations langagières, vol. II. Rouen: PUR., 2004.

BRONCKART, JP; DOLZ, Jaquim; Schneuwly, B. Géneros orais e escritos na escola. Campinas: Mercado de Letras, $2^{\mathrm{a}}$ Edição. 2007.

COSTA, António Fernandes da. A conceção eurocêntrica do universo linguístico em Angola e as suas consequências nocivas na difusão da Lingua Portuguesa. Braga: Universidade do Minho, 1992.

COSTA, António Fernandes da. Ruturas estruturais do Português e Linguas Bantu em Angola" Luanda: UCAN, 2006.

COUTINHO, M. A. \& outras. Géneros de textos e ensino de escrita. Aveiro: Universidade de Aveiro, 2012.

COUTINHO, M. A. Ecriture et rapport au savoir. In Enjeux (53). mars 2002. p. 176 - 187.

CUNHA C.; CINTRA Luís F. L. Nova Gramática do Português Contemporâneo. Lisboa:

Edições JSC, 2005. 
CUQ, Jean-Pierre (ouvrage coordonné par...). ASDIFLE. Dictionnaire de didactique du Français Langue Etrangère. Paris : CLE International. S. E. J. E. R., 2003.

OLIVEIRA, Anabela D. B de. (Org.). Dicionário de metalinguagens da didática. Porto: Porto Editora, 2000.

DEMIRTAS, Lokman e GUMUS, Huseyin. De la faute à l'erreur : une pédagogie alternative pour améliorer la production écrite en FLE. Université de Marmara. Synergies Turquie. 2009.

Dicionário da Lingua Portuguesa - Acordo ortográfico (antes e depois). Porto: Porto Editora, 2010.

DOLZ, J.; NOVERRAZ, Michèle; SCHNEUWLY, Bernard. Sequências didáticas para o oral e a escrita: apresentação de um procedimento. In ROJO, R.; CORDEIRO, G. (trad. e org.). Géneros orais e escritos na escola. Campinas: Mercado de Letras. 2004.

DUCROT, Jean-Michel. La pédagogie de l'erreur : corriger et remédier. Alep-Syrie. 2004.

FERNANDES, Verónica H. P. Marques. Os erros ortográficos em língua materna dos alunos do ensino básico na perspetiva do trabalho curricular dos professores. Porto: Universidade Portucalense Infante D. Henrique, 2008.

FONSECA, F. I. Pedagogia da Escrita. Perspetivas. Porto: Porto Editora, 1994.

FONSECA, Vítor da. Uma introdução às dificuldades de aprendizagem. Lisboa: Editorial Notícias, 1984.

GALISSON, Robert. Du structuralisme au fonctionalisme. Paris : CLE International, 1980.

GARGALLO, I. S. El análisis de errores en la interlengua del habitante no nativo. In LOBATO J.; GARGALLO, I. (Org.) Vademécum para la formación de profesores. Madrid: SGEL, 2004, p. 391-410.

GOMES, Álvaro. Imperativos pedagógicos didácticos para uma pax orthographica. Revista portuguesa de educação. Lisboa. 1990.

GOMES, Álvaro. Ortografia para todos - Para (ensinar a) escrever sem erros. Porto: Porto Editora, 2006.

INSTITUTO DE LEXICOLOGIA E LEXICOGRAFIA DA ACADEMIA DAS CIENCIAS DE LISBOA. Dicionário da Lingua Portuguesa Contemporânea. Lisboa: Editorial Verbo. 2001.

MADEIRA, Ana L. Aquisição de língua não materna. In SANTOS, Ana L.; FREITAS Maria J. Aquisição de língua materna e não materna. Berlin: Language Sciences Press, 2017.

MOREIRA, V.; PIMENTA, H. Gramática de Português - $3^{\circ}$ Ciclo do Ensino Básico e Secundário Porto: Porto Editora, 2017.

NIZA et all. Guião de Implementação do Programa de Português do Ensino Básico. Lisboa: Ministério de Educação, 2011. 
OLIVEIRA, Fernanda B. Análise ortográfica na produção de textos. Várzea Grande, MT: Univag, 2009.

PIETRO, J.-F., S. Erard; KANEMAN-POUGATCH, M. Un modèle didactique du "débat": de l’objet social à la pratique scolaire. Enjeux 39/40. 1996.

REIS, Carlos et al (Org.). Programas de português do ensino básico. Lisboa: Ministério da Educação; DGIDC, 2009.

REUTER, Y. Enseigner et apprendre à écrire : construire une didactique de l'écriture. Paris : ESF, 1997.

RICHARDS, Jack C. Error analysis, perspectives on second language acquisition. London: Longman, 1971.

SOUSA, Óscar C. de. Competência ortográfica e competências linguísticas. Lisboa: ISPA, 1999.

TAGLIANTE, Christine. La classe de langue. Paris : Clé International, 1985.

VITAL, Cláudia B. e CRISPIN, Karla G. M.. Aquisição da linguagem escrita: conhecer para intervir. Centro Universitário Nilton Lins, Amazónia. 1999.

ZORZI, Jaime Luiz. Aprender a escrever: a apropriação do sistema ortográfico. Porto Alegre: Artes Médicas. 1998.

ZORZI, Jaime Luiz. Fonoaudiologia na Educação e nos Distúrbios da Escrita. Rio de Janeiro: CEFAC. 1999.

Recebido em: 04/09/2019. Aprovado em: 16/01/2020. 


\section{ANEXOS}

1. Texto de estudo nas SD: A árvore que tinha batucada.

\section{A árvore que tinha batucada}

Pintadas de fresco na memória, cenas de "O Laço da Meia Noite"e passava entåo das onze da noite, vinha assim do cinema, noctivago, quase só. E vinha assim, andando e assim andando, passos quase na fronteira tuz e escuridaso. Tinha nó na garganta: o medo engravatado.

Siléncio cortado: cào a ladrar. E acelerei entlo: o passo. Cacimbante, luarenta: a noite. Capim seco tinha entalo cheiro de queimadura. E tinha pirilampo, pontinho luminoso: adiante. $\mathrm{Sem}$ intermitềncia, nầo era pirilampo: certifiquei. Experimentei entho descontrair assim: assobiando. Breve sensaço de segurança. Porém, as minhas pernas nło estavam entło a acompanhar o esforço para me descontrair assim. Pontinhos luminosos agora estavam entalo a aumentar. $\mathrm{E}$ parei: assustado. Mas, impenuosamente veio entăo assomo de coragem: decido, retomei o passo. Sobre a

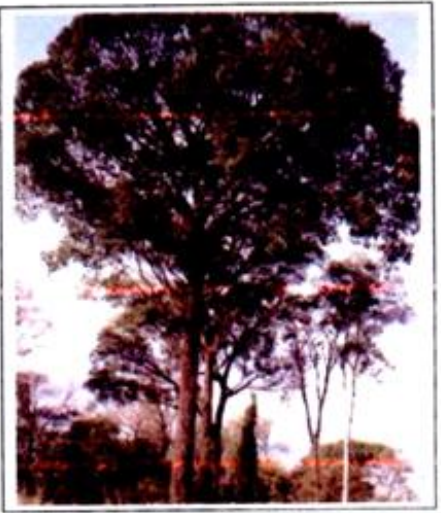
minha cabeça: os pontinhos luminosos. E dos lados: os pontinhos luminosns. Sem querer tossi entâo e alguém tossiu também. E tossi: tossiu. Tossia e na noite luarenta ecoavam tosses. E retive entao o passo assim e olhei assim para os lados: ninguém! Oh! Outra vez na passada. E assobiei entalo e o silếncio da noite que apenas de vez em quando era cortado pelo vento e o silêncio da noite se engravidou entâo de assobios. Fiu! Fiu! Fiu! E deixei ainda de assobiar, mas o silencio continuou a encher-se de assobios. Imobilizei entào de novo o passo. E ouvi entao vozes. Vozes. E decidi entho: passivo passo progressivo. E ouvi entilo, outra vez, vozes. Quem vem ai? _ quem falou assim fui eu. Quem vem af? _ Vozearam vozes. E parecia que as voves estavam a vir entåo de uma árvore que estava: próxima. E ventava. Capim seco e galhos secos comecavam entalo a rolar, a rolar, a rolar assim pelos carreiros muitos. Fantasmas pareciam. E estava entào calado. $\mathrm{O}$ eco é que entào continuon voreando. Quem vem aif!!! Quem vem ai?!!! E sentia-me pequeno perante uma voz tho potente e cavernosa. E comecei entåo a ouvir, vindo da árvore que agora estava à minha frente uma mistura de sons e ruidos e gargalladas $\mathrm{e}$ batucada $\mathrm{e}$ barulho de pratos $\mathrm{c}$ cales ladrando e gatos miando. E năo estava a ver ninguém. E nalo me atrevia a dar passo. E fiquei entào estático. Um som oco créscia e crescia assim: eram caboças entrechocando-se. E descernm enț̂o da írvore e vieram cotâo cí abaixo movimentando-se às voltas, dançando. E nào via ningucm. E de repente comecei entào a ser esbofeteado. E tentei esquivar-me: defender-me: $\mathrm{em}$ vào. E aguentei bofetadas e pontapés até cair no desmaio.

Um dia, vieram entllo caminhantes armados de catanas e machados para matar a árvore e ver entåo que é que cla tinha lá dentro. Queriam roubar as prendas valiosas que ela recebia de muitos caminhantes e que guardava entâo no seu corpo. E os caminhantes, depois de muitas horas c suados e extcruados, desistiram de a golpcar cow as catanas o as machados. E no corpo dela nào havia entlo nenhum sinal e nenhuma marca $\mathrm{e}$ nenhum golpe. Por isso os caminhantes desistiram.

E no começo da estrada que dava para a Kaála, frondosa e imponente: a árvore. Durante o dia cra igual a tantas outras. Nia sua sombra, os passantes vinham entalo refrescar-se e recobrar snergias para distíncia longa. E descontraidas as crianças entao: lúdicas. Durante o dis, era uma irvore normal e $s \mathrm{~cm}$ nenhum sinal estranho. De noite é que ninguém se atrevia então a ir la jatisfazer a curiosidade. $\mathrm{E}$ de dia uns olhavam-na: respeitosamente. Os mais velhos descobriam antâo a cabeça e inclinavain-se perante a ârvore. E tinha até gerte que mesmo de dia evitava passar por ela.

A Worte do Velho Kipakasca (extrasto) 


\section{Ficha informativa: técnicas de elaboração de resumo escolar}

\section{Técnicas de elaboração de resumo escolar}

\begin{tabular}{|c|c|}
\hline $\begin{array}{l}\text { Análise preli- } \\
\text { minar } \\
\text { do texto }\end{array}$ & $\begin{array}{l}\text { - Determinar o tipo de texto; } \\
\text { - Ler e dividir o texto em partes; } \\
\text { - Sublinhar as palavras-chave para identificar a rede semântica (significado das } \\
\text { palavras e/ou interpretação das frases); } \\
\text { - Identificar a organização do texto, resumir cada parte e colocar notas à mar- } \\
\text { gem; não omitir: referência a movimentos literários, políticos ou outros, nomes } \\
\text { próprios, termos técnicos, palavras de difícil substituição e datas importantes; } \\
\text { - Identificar os articuladores do discurso e as relações que estabelecem entre si. }\end{array}$ \\
\hline $\begin{array}{l}\text { Princípios bá- } \\
\text { sicos }\end{array}$ & $\begin{array}{l}\text { - Distinguir o essencial do acessório; } \\
\text { - Seguir uma correta articulação lógica das frases e dos parágrafos. }\end{array}$ \\
\hline Redação & $\begin{array}{l}\text { - Respeitar a sequência das ideias do texto original; } \\
\text { - Escrever uma oração simples por cada ideia principal e unir estas ideias me- } \\
\text { diante os conectores adequados; } \\
\text { - Evitar qualquer opinião pessoal ou comentário. O resumo deve ser impessoal; } \\
\text { - O resumo não deve ultrapassar um terço do número de palavras do texto- } \\
\text { fonte; } \\
\text { - Não usar expressões ou frases inteiras do texto-fonte; pode usar-se a rede } \\
\text { semântica identificada, colocando aspas; } \\
\text { - Não utilizar o diálogo. }\end{array}$ \\
\hline Regras & $\begin{array}{l}\text { - Suprimir as repetições, as fórmulas, as interjeições, os exemplos, as citações, } \\
\text { etc. ... } \\
\text { - Generalização: substituir alguns elementos da frase, como palavras ou ideias, } \\
\text { por outros mais gerais através do critério semântico; } \\
\text { - Seleção: distinguir bem o essencial do acessório, suprimindo os elementos } \\
\text { que exprimam pormenores, como adjetivos, advérbios e equivalentes; } \\
\text { - Construção: manter os tempos e pessoas gramaticais, respeitando a ordem do } \\
\text { texto-fonte, fazer tantos parágrafos quantas as partes que contiver o plano (as } \\
\text { ideias principais), conservar a estrutura do texto-fonte, ligar logicamente as fra- } \\
\text { ses redigidas. }\end{array}$ \\
\hline Técnicas & $\begin{array}{l}\text { - Substituir um grupo de palavras por uma única, por exemplo, por um nome, } \\
\text { por um adjetivo, por um verbo, por advérbio, etc..; } \\
\text { - Substituir uma enumeração por ou vários termos englobantes; } \\
\text { - Saber utilizar sinónimos; } \\
\text { - Manter o sistema de enunciação (utilizar o mesmo sistema pronominal - } \\
\text { manter os mesmos pronomes pessoais; } \\
\text { - Estabelecer as redes lexicais. }\end{array}$ \\
\hline
\end{tabular}

